\title{
Retinol-binding protein 4 levels are related to maternal triglyceride levels
}

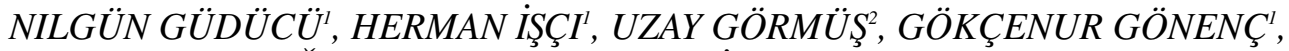 \\ ALIN BAŞGÜL YIĞITER ${ }^{l}$, BIROL ÖZTÜ̈RK ${ }^{3}$, ILKKAN DÜNDER ${ }^{l}$
}

${ }^{1}$ Department of Obstetrics and Gynecology, İstanbul Bilim University, Avrupa Hospital, İstanbul, Turkey

2İstanbul Bilim University, Department of Biochemistry, İstanbul, Turkey

${ }^{3}$ Department of Pediatry, İstanbul Bilim University, İstanbul, Turkey

\begin{abstract}
Aim of the study: To detect whether there is an association between interleukin $8(I L-8), I L-17$, retinol binding protein $4(R B P 4)$ and birth weight and maternal biochemical parameters.

Material and methods: We obtained simultaneous maternal and cord blood from 77 patients. Blood for RBP4, IL-8 and IL-17 was stored.

Results: There was no statistically significant correlation between maternal and cord blood RBP4, $I L-8, I L-17$ levels and birth weight percentiles. There was a statistically significant correlation between maternal RBP4 and maternal triglyceride and VLDL levels $(r=0.239 ; p=0.038$ and $r=0.278$; $p=0.038)$, between maternal IL-17 and maternal LDL levels $(r=0.253 ; p=0.031)$. There was a positive relation between RBP4 and maternal blood glucose in the bottom quartile group $\left(<25^{\text {th }}\right.$ percentile $)$ $(r=0.612 ; p=0.015)$.

Conclusion: Maternal RBP4 levels were related to maternal triglyceride levels. There was no association between RBP4, IL-8, IL-17 and birth weight.
\end{abstract}

Key words: retinol-binding protein 4, interleukin 8, interleukin 17, birth weight, pregnancy.

(Centr Eur J Immunol 2013; 38 (2): 221-225)

\section{Introduction}

Implantation is a controlled inflammatory process. An exaggerated response in this inflammatory process may lead to defective placentation, which results in "Great Obstetrical Syndromes" including fetal growth restriction and preeclampsia [1]. Many studies focused on specific inflammatory markers that would aid to define abnormalities in the inflammatory process of implantation and subsequent placentation.

Retinol binding protein 4 (RBP4) is an adipocytokine, and is also expressed by macrophages under the regulation of inflammatory stimuli [2]. Retinol binding protein 4 is a specific blood-carrier of retinol, and is overexpressed in adipose tissue of insulin-resistant and diabetic patients [3].

Subsequent reports regarding the association between maternal plasma RBP4 levels and gestational diabetes mellitus presented controversial results [4-6]. Retinol binding protein 4 was also reported to be expressed by macrophages and to be regulated by inflammatory stimuli [2]. Changes in RBP4 levels correlated with those of inflammatory markers [7]. Increased levels of the chemokine interleukin 8 (IL-8) was reported to be associated with fetal growth restriction in preeclamptic pregnancies [8] and IL-17 was reported as a proinflammatory cytokine that induced the secretion of IL-8 [9].

Previous studies comparing RBP4 levels with birth weight reported conflicting results [10-12]. We hypothesized that abnormalities in maternal RBP4 levels and the associated proinflammatory state, controlled by IL-8 and IL-17 levels, might affect birth weight. We compared RBP4 levels with maternal biochemical parameters. We also measured cord blood RBP4, IL-8 and IL-17 levels to control the related associations.

\section{Material and methods}

The study was designed as a prospective clinical study. The study protocol was designed according to the Decla-

Correspondence: Nilgün Güdücü, Assist. Prof., MD, Department of Obstetrics and Gynecology, İstanbul Bilim University, Kısıklı cad. No:106 Altunizade, 34692, İstanbul, Turkey, tel. +90 0533 6404010, fax +90 02163250104, e-mail: nilgun.kutay@ gmail.com 
ration of Helsinki. The individuals who had routine followup for pregnancy at the İstanbul Bilim University Department of Gynecology and Obstetrics between January 2010 and January 2012 were recruited for the study. The pregnants were fully informed about the details of the study. Informed consent was obtained from those who accepted to join the study.

Singleton pregnants who had C-section after the $36^{\text {th }}$ gestational week were included in the study. Exclusion criteria were:

- multifetal gestation,

- presence of ruptured membranes before delivery,

- presence of maternal diseases such as gestational diabetes mellitus, gastrointestinal malabsorptive diseases, hypertensive diseases of pregnancy, suspicion of infectious diseases,

- diagnosis of fetal anomalies (abnormal fetal karyotype, congenital malformations),

Table 1. Demographic features of the patients and maternal serum concentrations of the metabolic parameters

\begin{tabular}{lccc}
\hline Parameter & Range & Mean \pm SD & Median \\
\hline Maternal age (years) & $23-41$ & $31.5 \pm 4$ & 31 \\
\hline First trimester BMI $\left(\mathrm{kg} / \mathrm{m}^{2}\right)$ & $18-40$ & $23.3 \pm 3.8$ & 22.5 \\
\hline Birth weight (grams) & $1950-4300$ & $3420 \pm 461.7$ & 3420 \\
\hline $\begin{array}{l}\text { Gestational week at } \\
\text { delivery (weeks) }\end{array}$ & $36-41.3$ & $38.9 \pm 1.4$ & 38.86 \\
\hline Triglyceride (mg/dl) & $10-544$ & $259.7 \pm 97.9$ & 251.5 \\
\hline Insulin (mU/ml) & $0.6-60.5$ & $9.7 \pm 7.1$ & 7.1 \\
\hline CRP (mg/l) & $0.01-1.75$ & $0.47 \pm 0.4$ & 0.34 \\
\hline Cholesterol (mg/dl) & $37-343$ & $233.9 \pm 64.3$ & 245 \\
\hline HDL (mg/dl) & $19-155$ & $64.5 \pm 22.7$ & 65.5 \\
\hline LDL (mg/dl) & $12-238$ & $117.4 \pm 46.2$ & 114 \\
\hline VLDL (mg/dl) & $2-102$ & $51.7 \pm 19.1$ & 50 \\
\hline HOMA-IR & $0.1-21.4$ & $1.99 \pm 2.9$ & 1.2 \\
\hline
\end{tabular}

Table 2. Levels of maternal and cord blood RBP4, IL-8 and IL-17

\begin{tabular}{lccc}
\hline & Range & Mean \pm SD & Median \\
\hline Maternal RBP4 & $6.00-183.2$ & $80.7 \pm 35.4$ & 81.6 \\
\hline Maternal IL-8 & $0.02-12.5$ & $0.9 \pm 1.7$ & 0.39 \\
\hline Maternal IL-17 & $0.5-129.7$ & $13.3 \pm 19.5$ & 6.10 \\
\hline Cord RBP4 & $6.0-134.4$ & $61.9 \pm 26.6$ & 61.8 \\
\hline Cord IL-8 & $0.02-20.6$ & $1.5 \pm 3.4$ & 0.4 \\
\hline Cord IL-17 & $1.2-82.9$ & $18.6 \pm 16.7$ & 14.9 \\
\hline
\end{tabular}

- fetal distress,

- presence of meconium in the amniotic fluid,

- unwillingness to join the study.

Ten milliliters of maternal blood sample was drawn from the maternal peripheral vein. Maternal blood samples were equally divided into two dry vacutainer tubes. One tube was used immediately after sampling for detection of blood glucose, insulin, C-reactive protein (CRP), triglycerides (TG), low density lipoprotein (LDL), very low density lipoprotein (VLDL), high density lipoprotein (HDL), and total cholesterol, whereas the other tube was stored at $-80^{\circ} \mathrm{C}$ until biochemical analysis for RBP4, IL-8 and IL-17. Five milliliters of cord blood sample was obtained from the placental side of the cord after transection of the cord during $\mathrm{C}$-section, was kept in a dry vacutainer tube and was stored at $-80^{\circ} \mathrm{C}$ until biochemical analysis for RBP4, IL-8 and IL-17.

The concentrations of RBP4, IL-17, and IL-8 were determined by ELISA (enzyme-linked immunosorbent assay) utilizing RBP4 kit (Assaypro, Belgium), IL-17 kit (Cytoscreen, Nivelles, Belgium), and IL-8 kit (Invitrogen, Camarillo, CA), respectively. Insulin resistance was measured by homeostasis model assessment (HOMA) of insulin resistance using the following formula: HOMA-IR = fasting insulin $(\mathrm{mU} / \mathrm{ml}) \times$ fasting glucose $(\mathrm{mg} / \mathrm{dl}) / 405$. Gestational age was measured according to the last menstrual period or the crown-rump length within the first trimester.

Statistical analysis was made using NCSS (Number Cruncher Statistical System) 2007 and PASS (Power Analysis and Sample Size) 2008 Statistical Software (Utah, USA). Data showing demographic parameters were presented as mean values and standard deviation. The relationships between quantitative variables were studied by Spearman's correlation analysis. Kruskal-Wallis test was used for the comparison of continuous variables among groups. Multivariate regression analysis was employed to determine factors that correlated with maternal and cord blood variants. A $p$-value of less than 0.05 was considered to be statistically significant.

\section{Results}

The total number of subjects included in the study was 77. Demographic data and results of the biochemical parameters showing maternal metabolic status are presented in Table 1. The levels of RBP4, IL-8 and IL-17 in maternal and cord blood are presented in Table 2. Table 3 illustrates the comparison of maternal and cord blood levels of RBP4, IL-8 and IL-17 with birth weight percentiles. There was no statistically significant correlation between maternal and cord blood RBP4, IL-8, IL-17 levels and birth weight percentiles. Cord blood IL-8 and maternal IL-17 levels were higher in the bottom quartile group $\left(<25^{\text {th }}\right.$ percentile) but did not reach statistically significant levels. We also checked the correlation between birth weight and maternal and cord 
Table 3. The relationship between birth weight percentiles and maternal and cord blood RBP4, IL- 8 and IL-17 levels

\begin{tabular}{|c|c|c|c|c|}
\hline & \multirow{2}{*}{\multicolumn{3}{|c|}{ Birth weight }} & \multirow{4}{*}{$p$} \\
\hline & & & & \\
\hline & $<25^{\text {th }}$ percentile & $25^{\text {th }}-75^{\text {th }}$ percentile & $>7^{\text {th }}$ percentile & \\
\hline & Mean $\pm \mathrm{SD}$ (median) & Mean $\pm \mathrm{SD}($ median $)$ & Mean $\pm \mathrm{SD}($ median $)$ & \\
\hline Maternal RBP4 & $83.7 \pm 20.2(83.1)$ & $79.6 \pm 37.3(80.8)$ & $81.8 \pm 43.9(80.4)$ & 0.816 \\
\hline Maternal IL-8 & $1.6 \pm 3.1(0.6)$ & $0.7 \pm 1.1(0.4)$ & $0.7 \pm 1.4(0.4)$ & 0.205 \\
\hline Maternal IL-17 & $18.4 \pm 21.9(10.8)$ & $12.2 \pm 20.3(4.3)$ & $11.2 \pm 11.7(6.5)$ & 0.144 \\
\hline Cord RBP4 & $59.6 \pm 17.8(58.7)$ & $62.8 \pm 28.3(61.4)$ & $61.4 \pm 30.5(64)$ & 0.837 \\
\hline Cord IL-8 & $2.6 \pm 4.8(1.3)$ & $1.3 \pm 3.2(0.4)$ & $0.9 \pm 1.2(0.5)$ & 0.117 \\
\hline Cord IL-17 & $20.8 \pm 22.2(12.4)$ & $18.2 \pm 14.8(14.5)$ & $17.6 \pm 17.5(18.1)$ & 0.957 \\
\hline
\end{tabular}

Kruskal Wallis Test

Table 4. Correlation of maternal blood levels of RBP4, IL-8 and IL-17 with maternal metabolic parameters

\begin{tabular}{lcccccc}
\hline $\boldsymbol{n}=\mathbf{7 7}$ & \multicolumn{2}{c}{ RBP4 } & \multicolumn{2}{c}{ IL-8 } & \multicolumn{2}{c}{ IL-17 } \\
\cline { 2 - 8 } & $\boldsymbol{r}$ & $\boldsymbol{p}$ & $\boldsymbol{r}$ & $\boldsymbol{p}$ & $\boldsymbol{r}$ & $\boldsymbol{p}$ \\
\hline Triglyceride & 0.239 & $0.038^{*}$ & -0.144 & 0.214 & 0.003 & 0.980 \\
\hline Insulin & 0.099 & 0.391 & -0.012 & 0.915 & -0.215 & 0.060 \\
\hline TSH & -0.002 & 0.988 & -0.045 & 0.766 & -0.086 & 0.572 \\
\hline CRP & 0.102 & 0.377 & -0.086 & 0.459 & 0.022 & 0.847 \\
\hline Blood glucose & 0.097 & 0.403 & -0.107 & 0.353 & 0.092 & 0.424 \\
\hline Cholesterol & 0.005 & 0.969 & 0.055 & 0.633 & 0.138 & 0.230 \\
\hline HDL & -0.035 & 0.766 & 0.094 & 0.421 & 0.099 & 0.397 \\
\hline LDL & -0.155 & 0.191 & 0.084 & 0.479 & 0.253 & $0.031^{*}$ \\
\hline VLDL & 0.278 & $0.038^{*}$ & -0.076 & 0.580 & -0.077 & 0.572 \\
\hline HOMA-IR & 0.103 & 0.372 & -0.012 & 0.920 & -0.014 & 0.236 \\
\hline
\end{tabular}

$r$ : Spearman's Correlation Coefficient

$* p<0.05$

blood levels of RBP4, IL-8 and IL-17. There was no statistically significant relationship. Maternal RBP4 levels were in correlation with cord blood RBP4 levels $(r=0.616$; $p=0.001)$. Maternal IL-8 levels were in correlation with cord blood IL-8 levels ( $r=0.555 ; p=0.001)$. Maternal IL-17 levels were in correlation with cord blood IL-17 levels $(r=0.581 ; p=0.001)$.

Maternal biochemical parameters were compared with maternal levels of RBP4, IL-8 and IL-17 and the results are presented in Table 4 . There was a statistically significant correlation between maternal RBP4 levels and maternal triglyceride and VLDL levels $(r=0.239 ; p=0.038$ and $r=0.278 ; p=0.038$ ). There was also a statistically significant correlation between maternal IL-17 levels and maternal LDL levels $(r=0.253 ; p=0.031)$. When the maternal biochemical parameters were compared with RBP4, IL-8 and IL-17 according to percentile groups, the only positive correlation was observed between maternal RBP4 and glucose in the bottom quartile group $\left(<25^{\text {th }}\right.$ percentile $)$ $(r=0.612 ; p=0.015)$.

There was no correlation between maternal BMI and maternal biochemical parameters (RBP4 $r=0.047$, $p=0.687$; IL-8 $r=-0.036, p=0.757$; IL-17 $r=-0.146$, $p=0.208$; TG $r=-0.092, p=0.435$; insulin $r=0.221$, $p=0.055$; TSH $r=0.207, p=0.168$; CRP $r=0.037$, $p=0.753$; glucose $r=-0.057, p=0.623$; HDL $r=-0.115$, $p=0.327$; LDL $r=-0.184, p=0.122$; VLDL $r=-0.154$, $p=0.263 ;$ HOMA-IR $r=0.181, p=0.117$ ).

\section{Discussion}

In our study we attempted to determine the relationship between the controlled inflammatory process of implanta- 
tion and fetal growth restriction [1]. A shift toward IL-17 production was reported in preeclampsia $[13,14]$ and the same process was suggested to play a role in acute transplant rejection [15]. Interleukin 17 was suggested to be involved in recurrent pregnancy loss $[13,16]$. Previously, increased levels of IL-8 were reported in cord blood of preeclamptic pregnancies with fetal growth restriction $[8,17]$. In our study, slightly increased levels of maternal IL-17 and IL-8 in the group at the lowest birth weight quartile suggest an association between IL-17 and IL-8 and defective placentation. Many other studies tried to find evidence of the connection between cytokines and fetal growth. Gene polymorphisms associated with decreased levels of anti-inflammatory cytokines IL-4 and IL-10 were associated with the delivery of SGA infants [18]. Infants born SGA were also reported to have higher cord blood IL-6, TNF- $\alpha$ and CRP levels [19]. On the contrary, in another study TNF- $\alpha$ and IL-6 levels were not related to delivery of SGA infants, but to preterm delivery [18]. Cord levels of IL-6 were reported to decrease with the decreasing birth weight [20]. Levels of IL-8, IL-6, TNF- $\alpha$ and CRP were found to be increased in preeclamptic pregnancies [17]. All of these findings were suggestive of an association between interleukins and placentation defects.

Interleukin 8 was suggested to regulate angiogenesis in early pregnancy [21] and increased levels were reported in the decidual tissue [22]. Interleukin 8 was also shown to promote the migration of first trimester trophoblasts [23]. The maternal and fetal low grade inflammatory state seems to affect the implantation process. Future studies investigating the relationship between IL- 8 and IL-17 levels and birth weight in larger study groups may reach statistically significant results. Cord blood levels of IL-8 were higher in preeclamptic and normal pregnancies when compared to maternal blood levels [8]. In our study, both IL-8 and IL-17 levels were higher in cord blood when compared to maternal blood levels, too. Previously, most of the proinflammatory cytokines and RBP4 were shown not to cross the placenta $[24,25]$.

Previously a correlation between RBP4 levels and markers of inflammation in children was shown [7]. Another cytokine, adiponectin, was shown to decrease IL-8 and IL-6 secretion from endometrial stromal cells [26]. We searched for an association between RBP4 and the inflammatory markers, IL-8 and IL-17. Our study demonstrated that maternal and cord blood levels of RBP4 had no association with fetal birth weight and with IL-8 and IL-17 levels. Previously, high levels of cord blood RBP4 were suggested to be associated with the delivery of LGA/SGA neonates [10] but another study opposed these findings [12]. Giacomozzi et al. suggested an association between SGA infants and cord blood RBP4 levels [11], RBP4 levels were suggested to decrease in SGA infants independent of insulin resistance markers [11]. We did not control the fetal markers of insulin resistance in cord blood, but the maternal markers of insulin resistance were not correlated with RBP4 levels. The only correlation was observed between maternal glucose and RBP4 levels in fetuses of the bottom quartile. Previously plasma RBP4 levels were found to increase with increasing TG levels [6, 27, 28]. On the contrary, in a recent study no association was reported between maternal RBP4 levels and prepregnancy BMI, birth weight, parameters of insulin resistance and TG levels [29]. Higher maternal plasma levels of RBP4 were reported to be associated with larger neonates both in women with and without gestational diabetes mellitus [5], high maternal RBP4 concentrations were attributed to maternal glucose metabolism. In that study, overweight mothers had higher RBP4 levels and this suggested an association related to maternal adipose tissue mass, rather than glucose metabolism. In our study, maternal RBP4 levels correlated with TG levels, an indicator of maternal adipose tissue mass, but did not correlate with the markers of insulin resistance, this was in accordance with a previous study [28].

Circulating RBP4 levels were influenced by the retinol and iron status of the subjects [7]. Nearly all of our patients received multivitamin supplementations containing vitamin A and iron during pregnancy. We did not control the serum levels of these two metabolites and this might have affected the results. Another limitation of the study was the small number of fetuses in the bottom quartile. Exclusion of patients delivering vaginally and those in active labor might have helped us to escape from the confounding factors related to maternal and fetal stress.

In conclusion, the exaggerated inflammatory response in pregnancy may be associated with underdevelopment of the fetus. Maternal RBP4 levels are related to maternal TG levels. There was no association between birth weight and IL-8, IL-17 and RBP4 levels.

Authors declare non conflicts of interest.

\section{References}

1. Brosens I, Pijnenborg R, Vercruysse L, Romero R (2011): The "Great Obstetrical Syndromes" are associated with disorders of deep placentation. Am J Obstet Gynecol 204: 193-201.

2. Broch M, Ramírez R, Auguet MT, et al. (2010): Macrophages are novel sites of expression and regulation of retinol binding protein-4 (RBP4). Physiol Res 59: 299-303.

3. Yang Q, Graham TE, Mody N, et al. (2005): Serum retinol binding protein 4 contributes to insulin resistance in obesity and type 2 diabetes. Nature 436: 356-362.

4. Chan TF, Chen HS, Chen YC, et al. (2007): Increased serum retinol-binding protein 4 concentrations in women with gestational diabetes mellitus. Reprod Sci 14: 169-174.

5. Mazaki-Tovi S, Romero R, Vaisbuch E, et al. (2010): Retinolbinding protein 4: a novel adipokine implicated in the genesis of LGA in the absence of gestational diabetes mellitus. J Perinat Med 2010; 38: 147-155. 
6. Krzyzanowska K, Zemany L, Krugluger W, et al. (2008): Serum concentrations of retinol-binding protein 4 in women with and without gestational diabetes. Diabetologica 51: 15111522.

7. Balagopal P, Graham TE, Kahn BB, et al. (2007): Reduction of elevated serum retinol binding protein 4 (RBP4) in obese children by lifestyle intervention: association with subclinical inflammation. J Clin Endocrinol Metab 92: 1971-1974.

8. Laskowska M, Laskowska K, Leszczyńska-Gorzelak B, Oleszczuk J (2007): Comparative analysis of the maternal and umbilical interleukin-8 levels in normal pregnancies and in pregnancies complicated by preeclampsia with normal intrauterine growth and intrauterine growth retardation. J Matern Fetal Neonatal Med 20: 527-532.

9. Ito M, Nakashima A, Hidaka T, et al. (2010): A role for IL-17 in induction of an inflammation at the fetomaternal interface in preterm labor. J Reprod Immunol 84: 75-85.

10. Chan TF, Tsai YC, Wu CH, et al. (2011): The positive correlation between cord serum retinol-binding protein 4 concentrations and fetal growth. Gynecol Obstet Invest 72: 98-102.

11. Giacomozzi C, Ghirri P, Lapolla R, et al. (2010): Retinol-binding protein 4 in neonates born small for gestational age. J Endocrinol Invest 33: 218-221.

12. Laudes M, Oberhauser F, Bilkovski R, et al. (2009): Human fetal adiponectin and retinol-binding protein (RBP)-4 levels in relation to birth weight and maternal obesity. Exp Clin Endocr Diab 117: 146-149.

13. Saito S, Nakashima A, Shima T, Ito M (2010): Th1/Th2/Th17 and regulatory T-cell paradigm in pregnancy. Am J Reprod Immunol 63: 601-610.

14. Toldi G, Rigó J Jr, Stenczer B, et al. (2011): Increased prevalence of IL-17-producing peripheral blood lymphocytes in preeclampsia. Am J Reprod Endocrinol 66: 223-229.

15. Afzali B, Lombardi G, Lechler RI, Lord GM (2007): The role of T helper 17 (Th17) and regulatory T cells (T reg) in human organ transplantation and autoimmune disease. Clin Exp Immunol 148: 32-46.

16. Liu YS, Wu L, Tong XH, et al. (2011): Study on the relationship between Th17 cells and unexplained recurrent spontaneous abortion. Am J Reprod Immunol 65: 503-511.

17. Szarka A, Rigó J Jr, Lázár L, et al. (2010): Circulating cytokines, chemokines and adhesion molecules in normal pregnancy and preeclampsia determined by multiplex suspension array. BMC Immunol 11: 59.

18. Engel SA, Olshan AF, Savitz DA, et al. (2005): Risk of spontaneous preterm birth is associated with common antiinflammatory cytokine polymorphisms. Epidemiology 16: 478-486.

19. Amarilyo G, Oren A, Mimouni FB, et al. (2011): Increased cord serum inflammatory markers in small-for-gestational-age neonates. J Perinatol 31: 30-32.

20. Ødegård RA, Vatten LJ, Nilsen ST, et al. (2001): Umbilical cord plasma interleukin- 6 and fetal growth restriction in preeclampsia: a prospective study in Norway. Obstet Gynecol 98: 289-294.

21. Chen SU, Chou CH, Chao KH, et al. (2010): Lysophosphatidic acid up-regulates expression of growth-regulated oncogene-alpha, interleukin-8, and monocyte chemoattractant protein-1 in human first trimester trophoblasts: possible roles in angiogenesis and immune regulation. Endocrinology 151: 369379.

22. Segerer S, Kammerer U, Kapp M, et al. (2009): Upregulation of chemokine and cytokine production during pregnancy. Gynecol Obstet Invest 67: 145-150.
23. Hirota Y, Osuga Y, Hasegawa A, et al. (2009): Interleukin (IL)$1 \beta$ stimulates migration and survival of first trimester villous cytotrophoblast cells through endometrial epithelial cellderived IL-8. Endocrinology 150: 350-356.

24. Aaltonen R, Heikkinen T, Hakala K, et al. (2005): Transfer of proinflammatory cytokines across the placenta. Obstet Gynecol 106: 802-807.

25. Quadro L, Hamberger L, Gottesman ME, et al. (2004): Transplacental delivery of retinoid: the role of retinol-binding protein and lipoprotein retinyl ester. Am J Physiol Endocrinol Metab 286: E844-851.

26. Takemura Y, Osuga Y, Yamauchi T, et al. (2006): Expression of adiponecti receptors and its possible implication in the human endometrium. Endocrinology 147: 3203-3210.

27. Lee DC, Lee JW, Im JA. (2007): Association of serum retinol binding protein 4 and insulin resistance in apparently healthy adolescents. Metabolism 56: 327-331.

28. Khovidhunkit W, Pruksakorn P, Plengpanich W, Tharavanij T (2012): Retinol-binding protein 4 is not associated with insulin resistance in pregnancy. Metabolism 61: 65-69.

29. Vaisbuch E, Romero R, Mazaki-Tovi S, et al. (2010): Retinol binding protein 4- a novel association with early-onset preeclampsia J Perinat Med 38: 129-139. 